\title{
The Aachen Colloquium Moves in a New Direction
}

The change in the name of the Aachen Colloquium from "Automotive and Engine Technology" to "Sustainable Mobility" for the $29^{\text {th }}$ staging of the event makes a clear political statement. In another change, the conference took place in virtual form for the first time because of the coronavirus pandemic. A total of 780 participants and 37 exhibitors attended the online event on October 6 and 7, 2020, which had a program of around 100 technical presentations.

\section{UNUSUAL CIRCUMSTANCES}

The saying "The world is what you make of it" has acquired a whole new meaning in this time of crisis. The coronavirus led to the Aachen Colloquium being organized in a very different way and, for the first time, it was a completely digital event. The fact that despite this or perhaps because of this the organizers were willing and able to make the best of the situation became clear during the welcome meeting on the evening before the colloquium started. The conference organizers, Prof. Lutz Eckstein from the Institute for Automotive Engineering (ika) and Prof. Stefan Pischinger from the Chair of Internal Combustion Engines (vka) at RWTH Aachen University, gave a relaxed and light-hearted introduction to the activities of the following two days.

\section{EFFICIENT DESIGN FOR \\ THE MOBILITY SOLUTIONS OF TOMORROW}

As expected, they began by explaining the new title of the colloquium, which

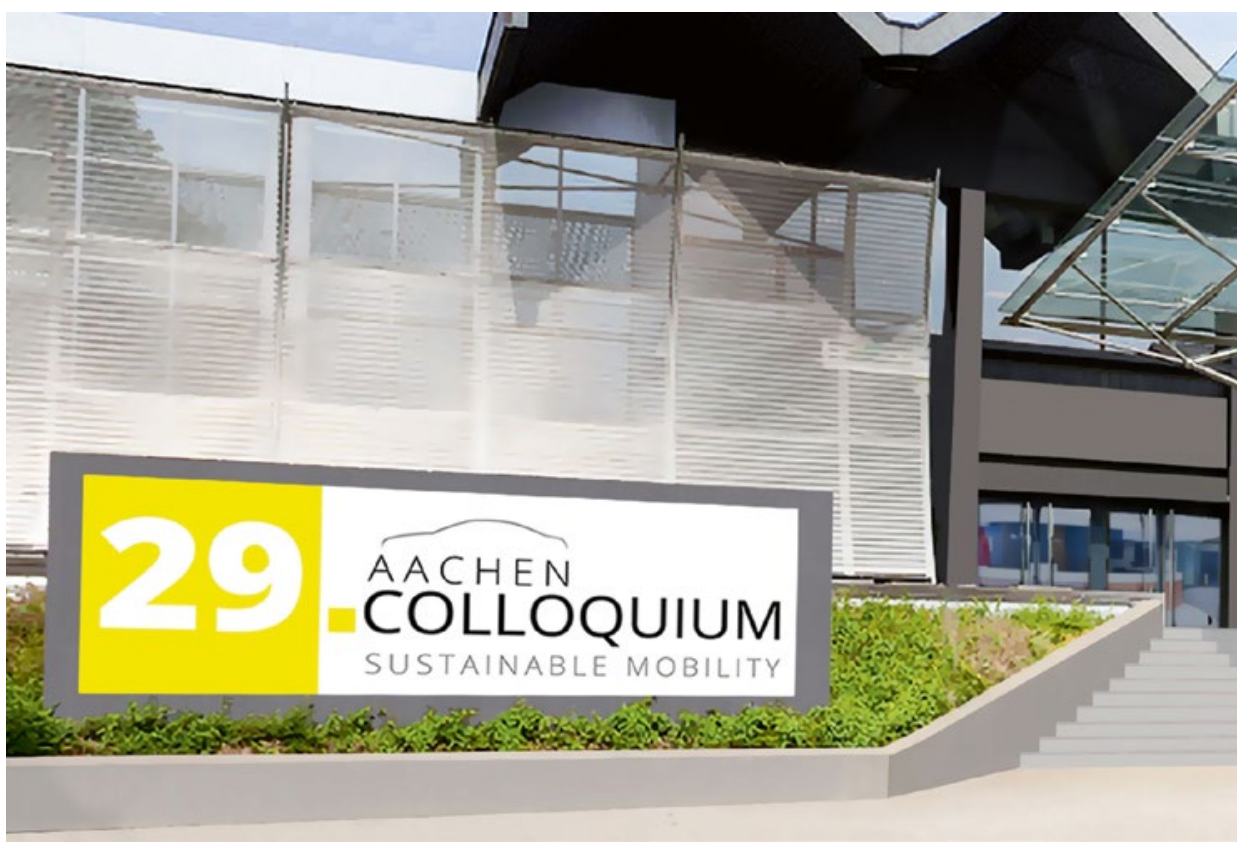

now goes under the banner of "Sustainable Mobility." Our mobility systems are facing many changes. Automated driving is opening up a new dimension, but it requires a quite different technical and legal framework. New fuels and powertrains will make climate neutrality possible and will also need a corresponding infrastructure. The growing demand for individual mobility and the increasing awareness of environmental issues are calling for approaches such as

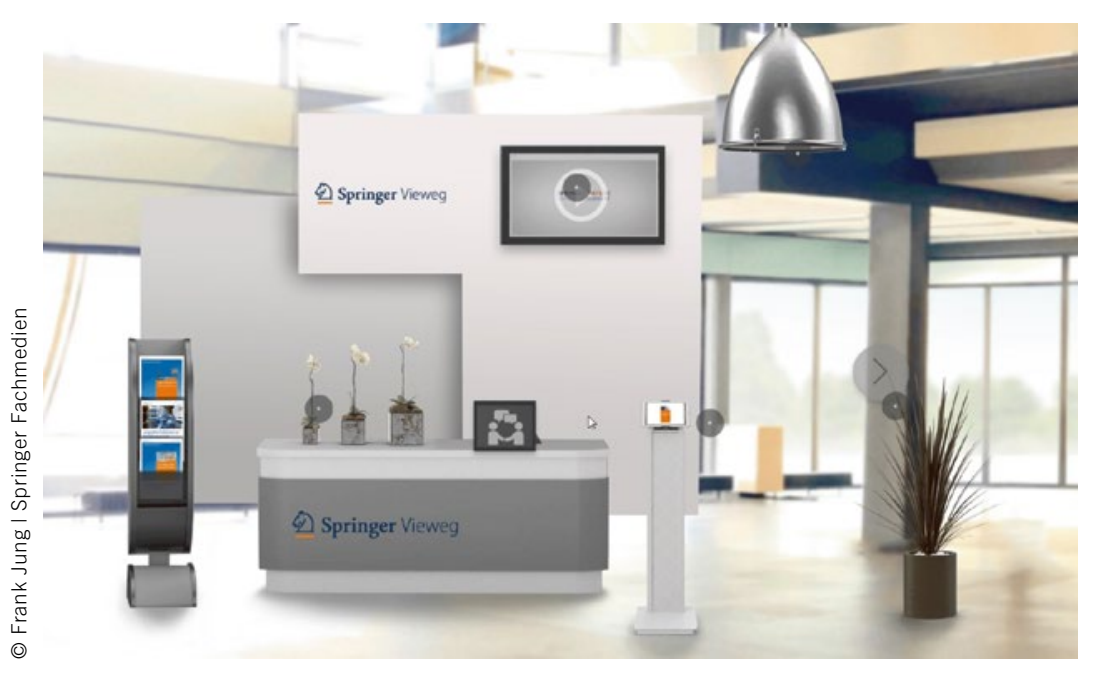

Springer Vieweg's virtual stand at the Aachen Colloquium enabled a great deal of interaction 
car sharing and air taxis, together with new vehicle concepts that will have to accompany them. One of the main challenges we currently need to overcome involves designing efficient, safe and

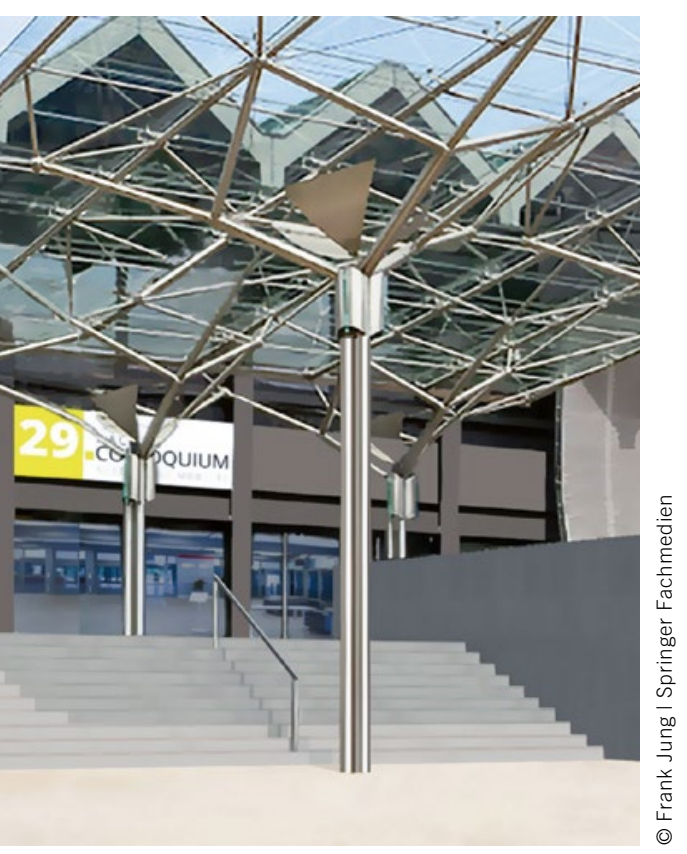

environmentally friendly mobility systems for tomorrow's world. "Climate change is real, regardless of what some old men in Washington claim," said Eckstein, aiming his criticism at the US president.

\section{DIRECT TO THE EVENT}

Pischinger regretted the fact that because of the circumstances it was not possible to meet in person and that he had had to make his own coffee, but in the spirit of making the best of the situation he also added: "But you can go directly from your breakfast table to the event."

Following the welcome gathering, the Kamm-Jante medals were awarded. Every two years they are presented to students, young scientists and engineers for outstanding achievements in the disciplines of automotive engineering and engine technology. The paper by Dr. Dominik Suckart entitled "Phenomenology and Modeling of Flame-Wall Interactions in Spark-Ignition Engines" was chosen in the field of engine technology by the jury who described it as excellent. The medal for automotive engineering went to Dr. Adrian Sonka for his paper "Classification and Prediction of the Traffic Environment for Automated Driving."

\section{DIGITAL CONFERENCE}

The next day, the digital conference began smoothly and without any technical glitches. The 780 participants had the opportunity to attend around 100 online technical presentations and plenary speeches on highly relevant subjects and to take part in discussions. The subjects included measures for achieving the $2050 \mathrm{CO}_{2}$ targets, electrification, zero-impact emission concepts and hydrogen applications, together with

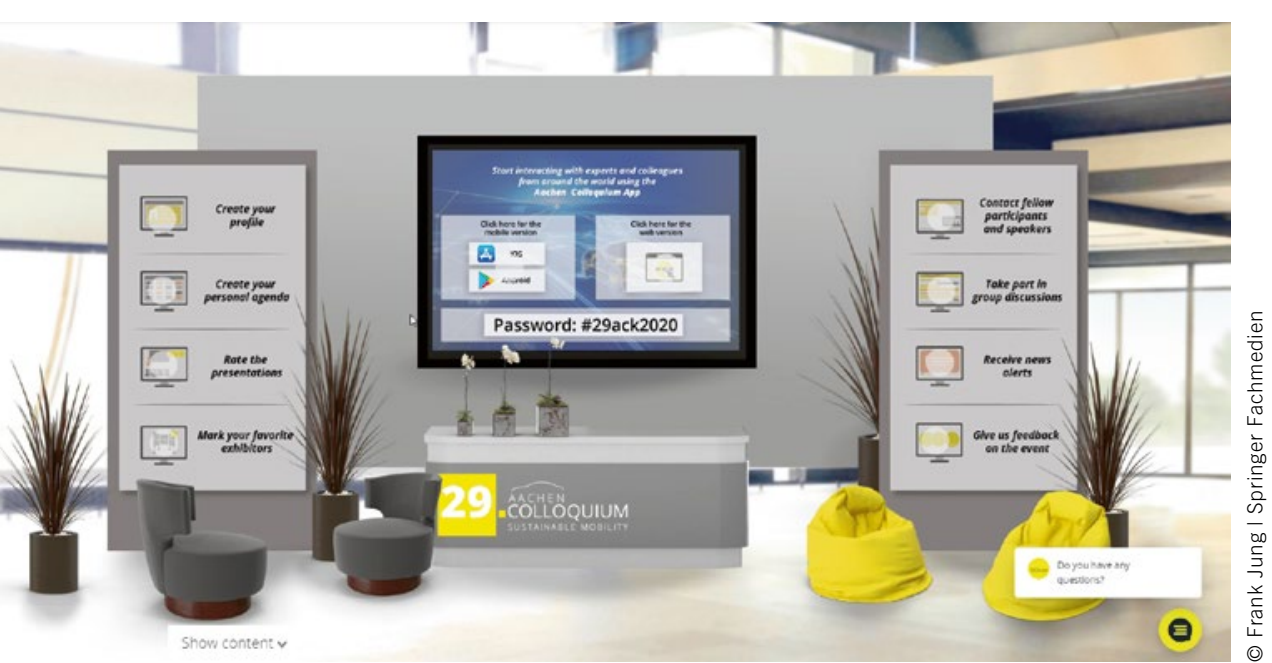

The virtual foyer provided visitors with a good opportunity to find their way around the entire online event

\section{QUOTES}

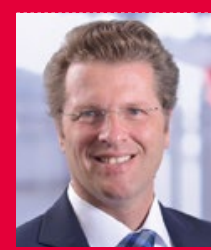

Lutz Eckstein,

RWTH Aachen University:

"Climate change is real,

regardless of what some

old men in Washington

claim."

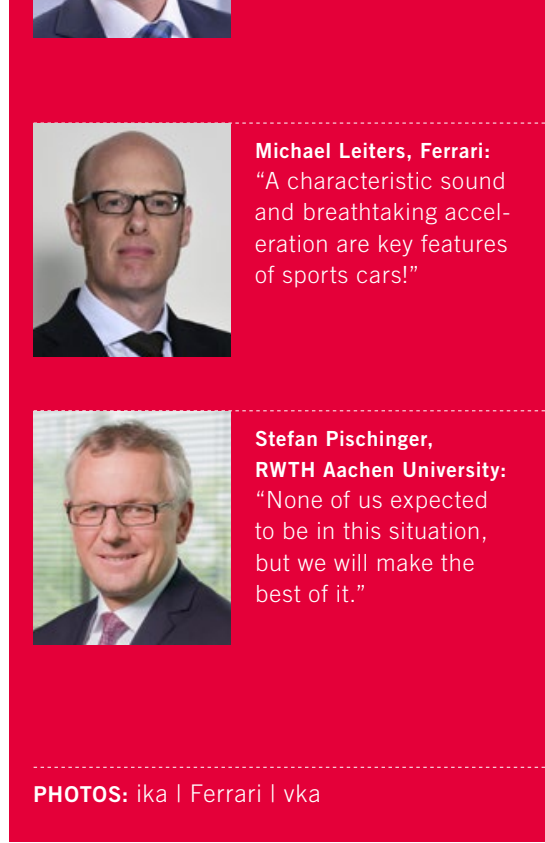

vehicle automation and the development of fully automated, driverless vehicles for different purposes. A total of 37 exhibitors took the chance to present their latest innovations at the digital exhibition, where visitors could obtain information and ask questions.

The program of presentations began with a plenary session where Dr. Michael Hugo Leiters, Chief Technology Officer of Ferrari, spoke on the subject of "Ferrari Emotion and Technology.” Prof. Andreas Pinkwart, Minister for Economic Affairs, Innovation, Digitalization and Energy of the German state of North Rhine-Westphalia, gave a presentation on the future of this federal state as a location for the automotive industry. Finally, Dr. Ulrich Lages, Chief Executive Officer of Ibeo, explained why lidar sensors are an essential feature of the vehicles of tomorrow. In the concluding plenary session on the last day, Prof. Udo Di Fabio, older of the Chair of Public Law at the University of Bonn, highlighted the legal and ethical framework needed for automated driving. 